\title{
The Classification Models Building of College Students' Physical Health and Its Development of Comprehensive Rating Scale

\author{
Wen-jie $\mathrm{LI}^{1, \mathrm{a}}$, Ling XIONG ${ }^{2, \mathrm{~b},{ }^{*}, \text { Jun WANG }}{ }^{3, \mathrm{c}}$, Meng $\mathrm{YU}^{4}$ \\ and Qian-long WANG \\ ${ }^{1}$ Department of Physical Education in Huazhong University of Science and \\ Technology, Wuhan, China

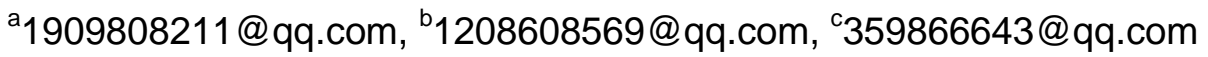

\begin{abstract}
Keywords: Physical constitution, Health evaluation, Classification of physical constitution, Mathematical models.
\end{abstract}

\begin{abstract}
Based on the physical health parameters of college students in China as well as taking the undergraduates of Huazhong University of Science and Technology as samples, by cluster analysis and discriminant analysis in mathematical statistic methods, the mathematical classification models of college students' physical constitution was established. By percentile method, it was able to develop a comprehensive rating scale of college students' physical health in order to provide scientific basis with the scientific classification of college students' physical constitution, comprehensive evaluation and sports prescription.
\end{abstract}

\section{Introduction}

The problems -- how to distinguish students in teaching according to their physical health and how to make exercise prescription according to the students' own physical health-- are worthy of discussion. In this study, taking the students in Huazhong University of Science and Technology (HUST) as samples, and with reference to physical fitness indicators of Chinese college students, the author will build mathematical models of a number of physical fitness indicators by the discriminant analysis to solve the problem of students' physical health classification, in addition, develop a comprehensive rating scale of college students' physical health with the use of percentile method. On the basis of this comprehensive rating scale, not only can it evaluate each student's physical health, but also can be targeted to make exercise prescription, in order to give the scientific and quantitative evaluation of college students' physical health.

\section{Subjects and Methods}

\section{Subjects}

By cluster sampling, 9765 students (male 6520, female 3245) in HUST are subjects in this detection research. The indicators of body shape include height, weight and bust; the indicators of body function involve vital capacity, heart rate, step test index; whereas the indicators of physical fitness consist of 50 meters, standing long jump, shot put, bend elbow, aerobic run $(1000 \mathrm{~m}$ for males and $800 \mathrm{~m}$ for females). Considered that body composition plays a great role in physical health, this research has tested body composition indicators of all subjects, including fat percentage, fat weight and fat-free weight. What's more, when developing the comprehensive rating scale of physical health in Chinese college students, meanwhile the author took a 
number of indicators of HUST students from 1995 to 2015 as a reference, combining with the statistics of physical health indicators of Chinese college students between 19 to 22 years old in Dictionary of School Physical Education, whose compilation was presided over by the Ministry of Education as well as the physical health indicators of college students in Hubei province published in 50th Anniversary of Sports Association of University in Hubei Province.

\section{Research Methods}

The data of all males and females in HUST respectively inputs into the computer, and then process the data with the software (Statistical Package for the Social Science).1) By using the method of cluster analysis, examinees' physical health indicators have been divided into 3 groups; 2) The discriminant function models on three kinds of males' and females' physical health indicators have respectively been established; 3) The data of all examinees' indicators should one by one be substitute into these models for testing the scientific rationality of these mathematical models. On the basis of statistics, if the model substitution rate reaches at $85 \%$, it follows that this mathematical model is considerably reliable.

In order to more clearly get to know a group's or a person's physical health, this paper developed a comprehensive rating scale of college students' physical health with percentile method. Moreover, it is easy to facilitate intuitive comparison for the evaluation results of percentage system.

\section{Establishment and Application of Mathematical Models}

\section{Establishing Mathematical Models}

By cluster analysis and establishing discriminant function models, it guaranteed that each individual exactly was classified into A, B, C categories. Table 1 and Table 2 are respectively shown that each parameter represents the indicators of male and female college students on physical health.

\section{The Mathematical Models of Males' Physical Health}

Table1. Each parameter represents respectively indicator of males

\begin{tabular}{|c|c|c|c|c|c|c|c|}
\hline Indicator & Parameter & Indicator & Parameter & Indicator & Parameter & Indicator & Parameter \\
\hline Height & $\mathrm{X} 1$ & $\begin{array}{c}\text { Vital } \\
\text { Capacity }\end{array}$ & $\mathrm{X} 4$ & $\begin{array}{c}\text { Fat-free } \\
\text { Weight }\end{array}$ & $\mathrm{X} 7$ & Shotput & $\mathrm{X} 10$ \\
\hline Weight & $\mathrm{X} 2$ & Fat & $\mathrm{X} 5$ & $50 \mathrm{M}$ & $\mathrm{X} 8$ & $\begin{array}{c}\text { Aerobic } \\
\text { Run } \\
\text { (1000m) }\end{array}$ & $\mathrm{X} 11$ \\
\hline Bust & $\mathrm{X} 3$ & Fat Weight & $\mathrm{X} 6$ & Standing & $\mathrm{X} 9$ & $\begin{array}{c}\text { Bend } \\
\text { Elbow }\end{array}$ & $\mathrm{X} 12$ \\
\hline
\end{tabular}

$\mathrm{A}=11.091 \mathrm{X} 1-10.168 \mathrm{X} 2+7.029 \mathrm{X} 3+0.0264 \mathrm{X} 4+18.526 \mathrm{X} 5-13.739 \mathrm{X} 6+5.680 \mathrm{X} 7+83.256$

$\mathrm{X} 8+2.033 \mathrm{X} 9+3.802 \mathrm{X} 10+0.142 \mathrm{X} 11+0.321 \mathrm{X} 12-1787.371$

$\mathrm{B}=11.013 \mathrm{X} 1-9.939 \mathrm{X} 2+7.018 \mathrm{X} 3+0.0546 \mathrm{X} 4+18.214 \mathrm{X} 5-13.464 \mathrm{X} 6+5.182 \mathrm{X} 7+84.20$

$7 \mathrm{X} 8+2.073 \mathrm{X} 9+3.507 \mathrm{X} 10+0.105 \mathrm{X} 11+0.335 \mathrm{X} 12-1884.067$ 
$\mathrm{C}=11.001 \mathrm{X} 1-10.072 \mathrm{X} 2+6.976 \mathrm{X} 3+0.0407 \mathrm{X} 4+18.614 \times 5-13.867 \mathrm{X} 6+5.625 \mathrm{X} 7+83.5$ $49 \times 8+2.058 \times 9+3.617 \times 10+0.117 \times 11+0.332 \times 12-1827.106$

\section{The Mathematical Models of Females' Physical Health}

Table2. Each parameter represents respectively indicator of females

\begin{tabular}{|l|l|l|l|l|l|l|l|}
\hline Indicator & Parameter & Indicator & Parameter & Indicator & Parameter & Indicator & Parameter \\
\hline Height & X1 & $\begin{array}{l}\text { Vital } \\
\text { Capacity }\end{array}$ & X4 & $50 \mathrm{M}$ & X7 & Sit-ups & X10 \\
\hline Weight & X2 & $\begin{array}{l}\text { Fat } \\
\text { Percentage }\end{array}$ & X5 & $\begin{array}{l}\text { Standing } \\
\text { Longjump }\end{array}$ & X8 & $\begin{array}{l}\text { Aerobic } \\
\text { Run(800m) }\end{array}$ & X11 \\
\hline Bust & X3 & Fat Weight & X6 & Shotput & X9 & & \\
\hline
\end{tabular}

$\mathrm{A}=9.997 \mathrm{X} 1-9.5 \mathrm{X} 2+12.49 \mathrm{X} 3+0.0566 \mathrm{X} 4+17.932 \times 5-20.818 \mathrm{X} 6+28.715 \times 7+1.875 \mathrm{X} 8+5$ $.135 \times 9+0.0158 \times 10+0.582 \times 11-1586.992$

$\mathrm{B}=9.935 \mathrm{X} 1-9.549 \times 2+12.54 \mathrm{X} 3+0.0874 \mathrm{X} 4+17.77 \times 5-20.426 \times 6+28.938 \times 7+1.859 \mathrm{X}$ 8+6.09X9-0.0744X10+0.606X11-1671.005

$\mathrm{C}=9.963 \times 1-9.549 \times 2+12.424 \mathrm{X} 3+0.0724 \mathrm{X} 4+17.929 \times 5-20.602 \times 6+28.66 \times 7+1.865$ X8+5.735X9-0.0589X10+0.59X11-1616.139

\section{Applying Mathematical Models}

Randomly choosing a male student as a sample, the computer substitutes respectively his each indicator into these three models, the maximum after computing represents that this male belongs to that category. For example, subject 172, his indicators (Table1)X1 $=176.7 \mathrm{~cm}, \mathrm{X} 2=67.2 \mathrm{~kg}, \mathrm{X} 3=83 \mathrm{~cm}, \mathrm{X} 4=3860 \mathrm{ml}, \mathrm{X} 5=18.80 \%, \mathrm{X} 6=12.6 \mathrm{~kg}$, $X 7=54.4 \mathrm{~kg}, X 8=7.3 \mathrm{~s}, X 9=234 \mathrm{~cm}, X 10=8 \mathrm{~m}, X 11=245 \mathrm{~s}, X 12=61 \mathrm{~s}$, respectively are substituted into model $A, B$ and $C$. The results are $A=1859.81 ; B=1858.29 ; C=1866.4$. Since the result of model $\mathrm{C}$ is the maximum, it follows that this subject belongs to category C. Similarly, subject 25 is a female, her indicators (Table2)X1 $=156.8 \mathrm{~cm}, X 2=45.8 \mathrm{~kg}, \quad X 3=78 \mathrm{~cm}, \quad X 4=2200 \mathrm{ml}, X 5=18.5 \%, X 6=8.5 \mathrm{~kg}$, $\mathrm{X} 7=8.5 \mathrm{~s}, \mathrm{X} 8=181 \mathrm{~cm}, \mathrm{X} 9=4.2 \mathrm{~m}, \mathrm{X} 10=33$ rep. $/ \mathrm{min}, \mathrm{X} 11=233 \mathrm{~s}$, respectively are substituted into model $A, B$ and $C$. The results are $A=1540.11 ; B=1521.76 ; C=1534.43$. Since the result of model $\mathrm{A}$ is the maximum, it follows that this female belongs to category A.

Undoubtedly, the computer software in this research could automatically substitute each indicator of all subjects one by one into these three models; meanwhile divide them into A,B,C categories in accordance with discriminant analysis. In addition, it also can test correct substitution rate. Nevertheless, the substitution rate for males in this paper reaches $95.1 \%$, and for female reaches $96.7 \%$. Therefore, it demonstrates that model A, B, C established in this research have good effect and importantly practical value. However, for those examinees who countenance a miscarriage of justice can be distinguished by these mathematical models to analysis between which two categories they place and make a judgment of their development trends. These lay a foundation to make sports prescription and "more bang for their buck". 


\section{Developing a Comprehensive Rating Scale of Physical Health}

This research had used a method of deviations from normal distribution and golden section to develop the rating scale; nevertheless, a satisfactory result was difficult to be achieved. The reason is that physical health indicators of college students are not normally distributed. Therefore, comparison with a number of methods, it is more proper to represent the dispersion of the observations by percentile method. A percentile is a measure used in statistics indicating the value below which a given percentage of observations fall. Based on all observations of a certain indicator, growing from small to big, all data is divided into 100 equal parts, and then percentile can reflect the position where an observation put in all data. This research divides each indicator into 7 percentiles to score. However, smaller data of some indicators is, higher score they get. It follows that this data is arranged in opposite direction to score objectively. The following Table 3 and Table4 are comprehensive rating scales of physical health of college male and female students.

Table3. A Rating Scale of physical health of college male students

\begin{tabular}{c|cccccc|c}
\hline Percentile & Height & Weight & Bust & Vital Capacity & Fat Percentage (\%) & Fat Weight & Score \\
\hline 92 & 178.9 & 70.8 & 89 & 4760 & 11.2 & 6.2 & 95 \\
84 & 176.5 & 65.5 & 86 & 4500 & 13.2 & 7.2 & 85 \\
70 & 173.3 & 59.2 & 83 & 4200 & 14.5 & 8.1 & 75 \\
56 & 171.2 & 58.7 & 82 & 4000 & 16.4 & 9.3 & 65 \\
42 & 168.3 & 55.9 & 80 & 3760 & 18.8 & 11.1 & 55 \\
28 & 166.5 & 53.7 & 78 & 3600 & 21.7 & 13.7 & 45 \\
14 & 164.3 & 51.1 & 76 & 3400 & 23.4 & 16.1 & 35 \\
92 & 6.6 & 259 & 9.5 & 91 & 190 & 64.74 & 95 \\
84 & 6.9 & 248 & 8.8 & 86 & 206 & 56.41 & 85 \\
70 & 7.2 & 237 & 8.2 & 72 & 222 & 53.22 & 75 \\
56 & 7.5 & 226 & 7.5 & 64 & 238 & 50.09 & 65 \\
42 & 7.8 & 214 & 6.9 & 56 & 254 & 47.62 & 55 \\
28 & 8.1 & 203 & 6.2 & 46 & 269 & 45.92 & 45 \\
14 & 8.4 & 192 & 5.6 & 37 & 285 & 43.69 & 35 \\
\hline
\end{tabular}

Application of the Comprehensive Rating Scale of College Students' Physical Health

For example, number 172 subject mentioned in this article below; looking up the tables, the average score of his 11 indicators is 65.9. So it shows that his physical health is at moderate level. While the average score of number 25 female examinee's 11 indicators is 62.3. Similarly, her physical health is at moderate level. The function 
of these tables also includes respectively scoring for body shape, body function, body composition and physical fitness, teachers can thereby targeted give scientific guidance and appropriate sport prescription according to students' weakness. Even each indicator of national, provincial or a class and individual is marked in rating scale in different- colored curves, at a glance, it is easy to make comparison and understand the physical constitution of a person or a group.

Table4. A Rating Scale of physical health of college female students

\begin{tabular}{|c|c|c|c|c|c|c|c|}
\hline $\begin{array}{l}\text { Percen } \\
\text { tile }\end{array}$ & Height & Weight & Bust & $\begin{array}{l}\text { Vital } \\
\text { Capacity }\end{array}$ & $\begin{array}{l}\text { Fat } \\
\text { Percentage } \\
(\%)\end{array}$ & $\begin{array}{l}\text { Fat } \\
\text { Weight }\end{array}$ & Score \\
\hline 92 & 166.8 & 60.1 & 88 & 3400 & 21.2 & 18.2 & 95 \\
\hline 84 & 165.8 & 57.3 & 85 & 3200 & 24.3 & 17.0 & 85 \\
\hline 70 & 163.5 & 54.9 & 83 & 3100 & 26.2 & 16.3 & 75 \\
\hline 56 & 161.2 & 52.7 & 81 & 2900 & 28.3 & 14.8 & 65 \\
\hline 42 & 158.9 & 50.4 & 79 & 2600 & 29.7 & 13.5 & 55 \\
\hline 28 & 156.7 & 48.2 & 77 & 2400 & 30.6 & 12.1 & 45 \\
\hline 14 & 153.9 & 41.9 & 72 & 2100 & 31.5 & 9.60 & 35 \\
\hline $\begin{array}{l}\text { Percen } \\
\text { tile }\end{array}$ & $50 \mathrm{~m}$ & $\begin{array}{l}\text { Standing } \\
\text { Longjump }\end{array}$ & Shotput & Sit-ups & Aerobic Run & $\begin{array}{l}\text { Step Test } \\
\text { Index }\end{array}$ & Score \\
\hline 92 & 8.5 & 195 & 6.0 & 40 & 220 & 76.87 & 95 \\
\hline 84 & 8.8 & 190 & 5.5 & 38 & 228 & 69.06 & 85 \\
\hline 70 & 9.0 & 185 & 5.2 & 36 & 233 & 58.82 & 75 \\
\hline 56 & 9.4 & 180 & 4.6 & 33 & 244 & 54.55 & 65 \\
\hline 42 & 9.8 & 170 & 4.4 & 28 & 255 & 51.68 & 55 \\
\hline 28 & 10.0 & 165 & 4.2 & 25 & 260 & 46.53 & 45 \\
\hline 14 & 10.4 & 155 & 4.0 & 20 & 270 & 44.33 & 35 \\
\hline
\end{tabular}

\section{Conclusions}

"Enhancing physical constitution and promoting health" are the guiding ideology of school physical education. If a good solution to use scientific quantitative evaluation of college students' constitution is absent, it is difficult to get out of the misunderstandings in competitive sports merely by qualitative methods to assess.

Based on the physical health parameters of college students in China as well as taking the undergraduates of HUST as samples in this article, the mathematical classification models of college students' physical constitution were established and a comprehensive rating scale of college students' physical health was developed in order to put college students' physical constitution on the same platform. Thus it is scientific, practical and comparable. However, there may be more typical indicators not selected in this research, we still believe that there were ways and methods to solve this problem and other problems will also be solved. 


\section{Acknowledgement}

I would like to express my gratitude to all those who helped me during the writing of this thesis.

My deepest gratitude goes first and foremost to Professor Wenjie Li, my supervisor, for his constant encouragement and guidance. I also owe my sincere gratitude to my fellow classmates who helped me work out my problems during the difficult cause of the thesis.

\section{Reference}

[1] Wenjie Li, On Study of Differences in Blood Lipids between Middle - aged and Old Patients with Coronary Heart Disease and Common Examinees by Discriminant Analysis, Journal of Wuhan Medical College. 1987(3-4). [In Chinese]

[2] Wenjie Li, Establishment of Mathematics Models of Body Fat and Blood Lipid for Postgraduates and Undergraduates, Journal of Hubei Sports Science. 1998(3). [In Chinese]

[3] Wenjie Li, Establishment of Quantitative Teaching Mode and Sports Prescription, Sports Communication. 1988(2-3). [In Chinese]

[4] Wenjie Li, Establishment of Chinese college students' constitution models, Higher Education Research. 1988 (2). [In Chinese]

[5] Wenjie Li, Exploration on Groups in Body-building Teaching by Body Fat Content, Journal of Wuhan Institute of Physical Education. 1996 (1). [In Chinese]

[6] Shaoping Zhao, Investigation Research on University Freshmen's Physical Constitution in Wuhan, Journal of Wuhan Institute of Physical Education. 2005 (4). [In Chinese] 